Journal for ImmunoTherapy of Cancer

\title{
Intermediate monocytes induced by IFN- $\gamma$ inhibit cancer metastasis by promoting NK cell activation through FOXO1 and interleukin-27
}

\author{
Rikang Wang, ${ }^{1,2}$ Weili Bao, ${ }^{3}$ Mouli Pal, ${ }^{3}$ Yunfeng Liu, ${ }^{3}$ Karina Yazdanbakhsh, ${ }^{3}$
} Hui Zhong (ID ${ }^{1}$

To cite: Wang R, Bao W, Pal M, et al. Intermediate monocytes induced by IFN- $\gamma$ inhibit cancer metastasis by promoting NK cell activation through F0X01 and interleukin-27. Journal for ImmunoTherapy of Cancer 2022;10:e003539. doi:10.1136/ jitc-2021-003539

- Additional supplemental material is published online only. To view, please visit the journal online (http://dx.doi.org/10. 1136/jitc-2021-003539).

Accepted 15 December 2021

Check for updates

(c) Author(s) (or their employer(s)) 2022. Re-use permitted under CC BY-NC. No commercial re-use. See rights and permissions. Published by BMJ.

${ }^{1}$ Laboratory of Immune Regulation, New York Blood Center, New York, New York, USA ${ }^{2}$ College of Pharmacy, Jiangxi University of Chinese Medicine, Nanchang, Jiangxi, China ${ }^{3}$ Laboratory of Complement Biology, New York Blood Center, New York, New York, USA

Correspondence to

Dr Hui Zhong; hzhong@nybc.org

\section{ABSTRACT}

Background Circulating monocytes are functionally heterogeneous and can be divided into classical (CMo), intermediate (IMo), and non-CMo/patrolling monocyte (PMo) subsets. CMo can differentiate into PMo through IMo. PMos have been shown to inhibit cancer metastasis but the role of IMo is unclear. To date, no strategy has been developed to inhibit cancer metastasis through enhancing PMo/IMo differentiation.

Methods We screened multiple inflammatory cytokines/ chemokines activity of modulating PMo/IMo associated cell markers expression using human monocyte in vitro culture system. We tested our candidate cytokine activity in vivo using multiple mice models. We identified critical key factors and cytokines for our candidate cytokine activity by using gene-knockout mice and neutralization antibodies. Results We identified IFN- $\gamma$ as a candidate inflammatory cytokine in the regulation of human IMo/PMo marker expression. Our in vivo data demonstrated that IMo expansion was induced by short-term (3 days) IFN- $\gamma$ treatment through increasing $\mathrm{CM}$-IMo differentiation and blocking IMo-PMo differentiation. The IMo induced by IFN- $\gamma$ (IFN-IMo), but not IFN- $\gamma$ activated CMo (IFN$\mathrm{CMo}$ ), inhibited cancer metastasis by $90 \%$. Surprizing, the effect of IFN- $\gamma$ is greater in PMo deficiency mice, indicating the effect of IFN-IMo is not mediated through further differentiation into PMo. We also found that IFNIMos induced by short-term IFN- $\gamma$ treatment robustly boosted NK cell expansion for threefold and promoted NK differentiation and function through IL-27 and CXCL9. Furthermore, we identified that FOX01, a key molecule controlling cellular energy metabolism, mediated the effect of IFN- $\gamma$ induced IL-27 expression, and that NR4A1, a key molecule controlling PMo differentiation and inhibiting cancer metastasis, inhibited the pro-NK cell and antimetastasis activity of IFN-IMo by suppressing CXCL9 expression.

Conclusions We have discovered the antimetastasis and pro-NK cell activity of IFN-IMo, identified FOX01 as a key molecule for IFN- $\gamma$ driven monocyte differentiation and function, and found NR4A1 as an inhibitory molecule for IFN-IMo activity. Our study has not only shown novel mechanisms for a classical antitumor cytokine but also provided potential target for developing superior monocytic cell therapy against cancer metastasis.

\section{BACKGROUND}

Monocytes are a heterogeneous cell population comprising of at least three subsets: classical monocytes (CMo, CD14 ${ }^{\text {high }}$ CD16- in humans, Ly6C ${ }^{\text {high }}$ TREML4- in mice), intermediate monocytes (IMo, CD14 ${ }^{\text {high }} \mathrm{CD} 16+$ in human, Ly6C+TREML4+in mice), and patrolling monocytes (PMo, CD14 ${ }^{\mathrm{dim}} \mathrm{CD} 16+$ in human, Ly6C-TREML4+in mice). ${ }^{1}$ It is widely accepted that PMo differentiate from CMo through IMo although some controversy remains. ${ }^{2}$ Multiple transcription factors, including NR4A1, ${ }^{3} \mathrm{C} / \mathrm{EBP} \beta^{4}$ and $\mathrm{Klf} 2,{ }^{5}$ have been identified as critical for PMo differentiation. Among them, NR4A1 has proven to be the pivotal transcription factor for PMo differentiation and survival. In contrast to PMo, IMo is considered a transient stage in the CMo to PMo differentiation under physiological conditions, but little is known about the mechanisms that control IMo differentiation.

Monocyte subsets produce different cytokines and exhibit distinct functions in health and disease environments. ${ }^{16}$ Previous reports showed that PMo, but not CMo, reduce lung metastatic burden in mouse by recruiting NK cell and controlling activating and stimulatory receptors expression on NK cell. ${ }^{78}$ The role of IMo in cancer metastasis is unclear because it is a transient stage under physiological condition and that the mechanism of IMo expansion in inflammatory diseases is unclear. So far, no strategy has been developed to inhibit cancer metastasis through inducing PMo/IMo expansion.

The expansion of PMo/IMo have been found in various inflammatory diseases, ${ }^{1}$ suggesting that monocyte subset differentiation is likely altered in these pathologies. However, because most studies on peripheral monocyte differentiation have been performed under normal physiological 
conditions, the mechanism controlling monocyte subsets differentiation in disease states remains largely unknown. Interestingly, inflammatory cytokines are known to regulate IMo and PMo associated cell marker expression. For example, IFN- $\gamma$ and IL-10 increase monocyte CX3CR1 expression ${ }^{9}$ while IL-21 supports monocyte CD16 expression $^{10}$ and IL-4 inhibits CD14 expression during monocyte to dendritic cell differentiation. ${ }^{11}$ However, the ability of these inflammatory cytokines inducing PMo/ IMo expansion are not known.

In this study, we identified IFN- $\gamma$ as a candidate inflammatory cytokine in the regulation of human IMo/PMo marker expression. Through in vivo studies, we demonstrated that IFN- $\gamma$ induced IMo expansion. Importantly, IFN- $\gamma$ induced IMo (IFN-IMo) inhibited cancer lung metastasis by inducing NK cell expansion through IL-27. Furthermore, we found that FOXO1 is a critical transcription factor for IFN-IMo activity and that NR4A1 is an inhibitory molecule for the pro-NK cell and antimetastasis activity of IFN- $\gamma$. Altogether, we have unveiled the ability of short term IFN- $\gamma$ treatment against cancer metastasis through IMo-FOXO1-IL-27-NK axis, demonstrated the potent anti-metastasis activity of IFN-IMo, and identify FOXO1 and NR4A1 as potential therapeutic targets for improving IFN- $\gamma$ treatment effect on cancer metastasis.

\section{METHODS}

Detailed experimental procedures are outlined in online supplemental data. Briefly, human and mouse (including C57/BL6, NR4A1-/-, E2-/-, STAT1-/-, and FOXO1 \pm mice) monocyte profiles were analyzed after IFN- $\gamma$ treatment for 3 days by flow cytometry. Antimetastasis effects of IFNIMos were evaluated in melanoma (B16F10 cell line) and Lewis lung carcinoma (LLC) mouse models. The role of IL-27 and FOXO1 were identified by analyzing gene expression changes and through functional blocking experiments.

\section{RESULTS \\ IFN- $\gamma$ enhances IMo expansion by inducing CMo-IMo expansion and blocking IMo-PMo differentiation}

The expression profile of five IMo/PMo associated markers, including the prototypic CD14 and CD16 monocyte markers as well as CX3CR1, CCR2, CD36, differs significantly between human CMo, IMo and PMo (figure 1A,B) with PMos expressing higher levels of CD16, CX3CR1 but lower levels of CD36, CCR2 and CD14 relative to CMo. We reasoned that any candidate factor for promoting IMo/ PMo differentiation would increase monocyte CD16, and CX3CR1 but inhibit CD36, CCR2 and CD14 expression. Based on a literature search, ${ }^{12-21}$ we selected 17 candidate cytokines/chemokines, each previously shown to modulate $\mathrm{IMo} / \mathrm{PMo}$ associated markers expression. IMo/PMo differentiation occurs within days in vivo. ${ }^{22}$ We used a shortterm (3 days) in vitro culture system to screen these 17 cytokines/chemokines. Of these, IFN- $\gamma$ was the most effective in altering the IMo/PMo associated marker expression, mimicking the differential expression pattern of PMo vs CMO (figure 1C). Indeed, IFN- $\gamma$ led to increased levels of CD16, and CX3CR1 but inhibited CD14 and CD36 expression on human monocytes along with a minor effect on CCR2 expression. The effect of IFN- $\gamma$ was dose dependent, increasing CD16 expression by 50\%, and CX3CR1 20 folds while inhibiting CD14 and CD36 by 50\% at the highest concentration tested (figure 1D).

We next examined the effect of IFN- $\gamma$ on IMo/PMo differentiation in vivo. C57BL/6 mice were intravenous injected with IFN- $\gamma(2.5 \mu \mathrm{g} / \mathrm{mouse}$, twice per day because of short half-life of IFN- $\gamma$ ) for 3 days. Circulating monocytes, defined as CD45 +CD11b ${ }^{\text {high }}$ Ly6G-CD115+cells and

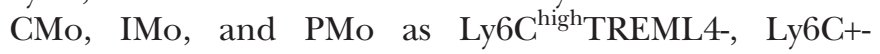
TREML4+, and Ly6C-TREML4+cells under total monocyte gate, respectively, were analyzed by flow cytometry (figure 1E). ${ }^{23}$ Monocyte derived dendritic cells and/ or M1 M $\Phi$ (DC/M,$~ \sim 1 \%$ in peripheral blood, 7\% in the spleen) defined as CD11c ${ }^{\text {high }}$ MHCII $^{\text {high }}$ cells under CD11 b ${ }^{\text {hi }} \mathrm{CD} 115$ +gate, the majority of which were TREML4-, were excluded from the analysis. The overall flow cytometry gating strategy was showed in online supplemental figure S1A. We found that IFN- $\gamma$ treatment increased IMo frequency $(\sim 80 \%)$ and decreased PMo frequency $(\sim 50 \%)$ in both total monocyte and white blood cell (WBC) populations (figure $1 \mathrm{~F}$ ). The similar IMo expansion was found in the spleen and bone marrow after IFN- $\gamma$ treatment (online supplemental figure S1B,C). Based on the widely accepted model that IMos develop from CMo and further differentiate into PMos, our results indicate that IFN- $\gamma$ induces IMo expansion in vivo by driving CMo differentiation and/or inhibiting PMo differentiation.

To identify whether IFN- $\gamma$ inhibits differentiation of PMo from IMo, we tested the effect of IFN- $\gamma$ on PMo expansion using muramyl dipeptide (MDP) which is known to increase PMo numbers. ${ }^{22}$ C57BL/6 mice were treated with MDP (10 mg/ $\mathrm{kg}$ mice body weight) with/without IFN- $\gamma$ for 3 days (figure $1 G$ ). We found that MDP treatment induced PMo expansion (PMo frequency increased from $20 \%$ in 'before' to $68 \%$ in 'Treatment') as previously reported (figure 1), but this effect was significantly inhibited by IFN- $\gamma$ cotreatment (MDP $+\mathrm{IFN}-\gamma$ ) (figure $1 \mathrm{H}, \mathrm{I}$ 'Treatment' time point). Indeed, in MDP +IFN- $\gamma$ group, the majority of IMos were blocked at the IMo to PMo stage based on Ly6C and TREML4 expression pattern (figure $1 \mathrm{H}, \mathrm{I}$ ). After stopping IFN- $\gamma$ and MDP treatment for 3 days ('off' time point), IMo frequency decreased while PMo frequency increased (online supplemental figure S1D), indicating that monocytes which are blocked at IMo stage by IFN- $\gamma$ treatment can further develop into PMo in the absence of IFN- $\gamma$. Altogether, these data support the conclusion that an IFN- $\gamma$ blocked IMo differentiation into PMo.

To determine whether IFN- $\gamma$ enhances IMo differentiation from $\mathrm{CMo}$, we tested the effect of IFN- $\gamma$ in PMo deficient mice (NR4A1-/-). Treatment of NR4A1-/- mice with IFN- $\gamma$ for 3 days led to a robust expansion of IMo as 


\section{A}

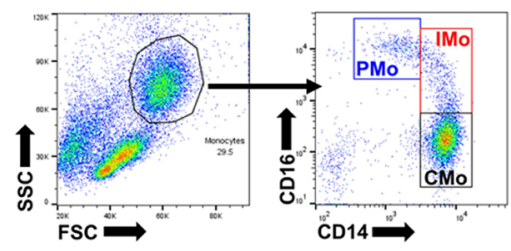

B

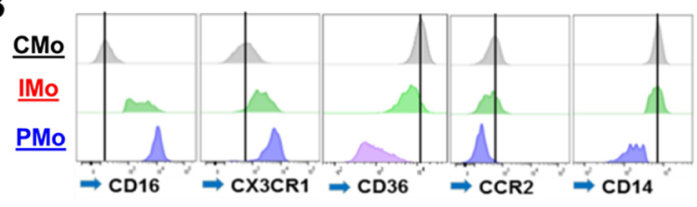

C
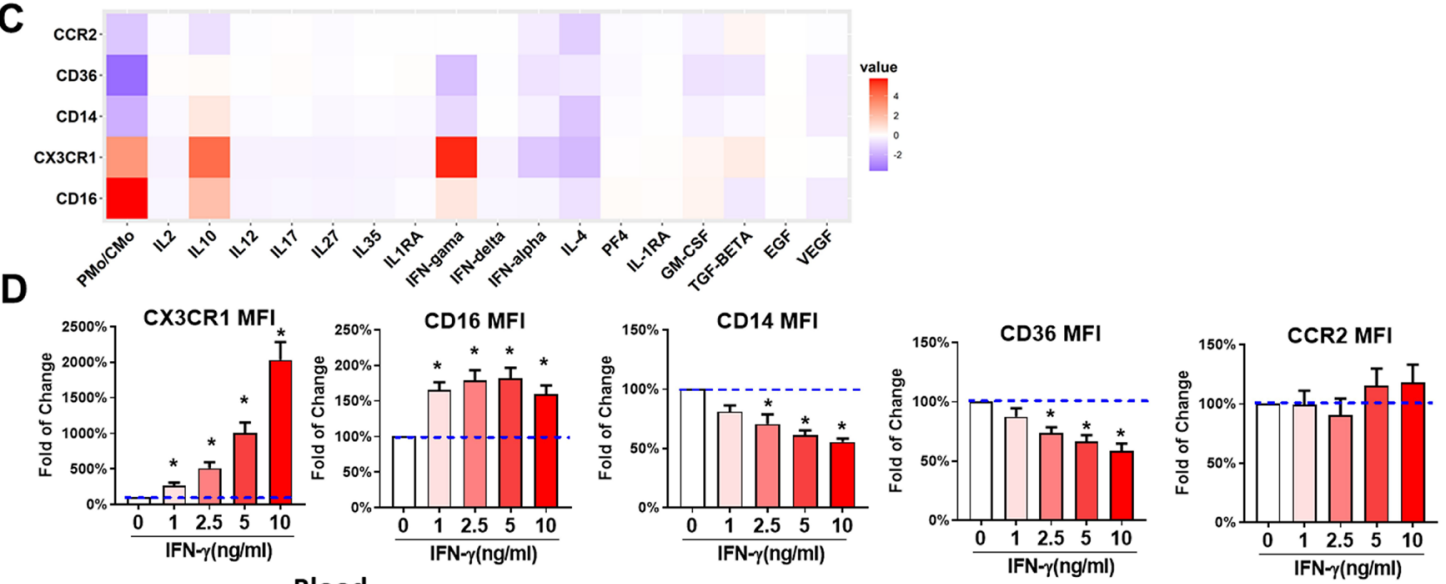

E
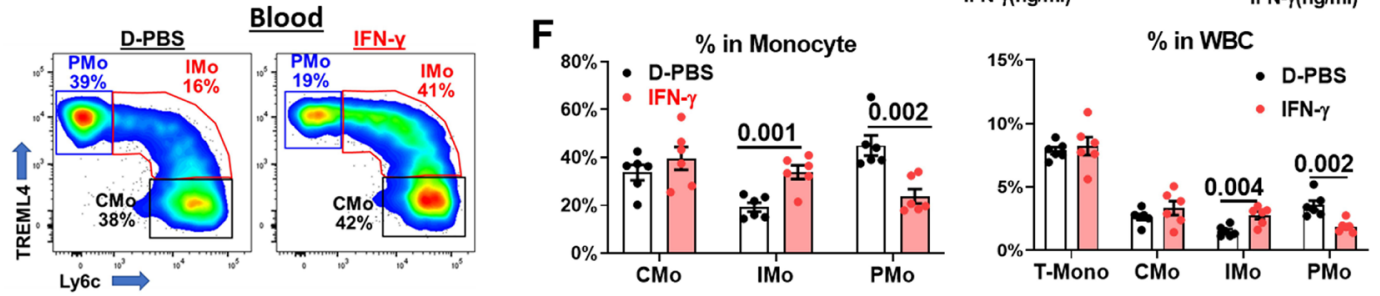

G
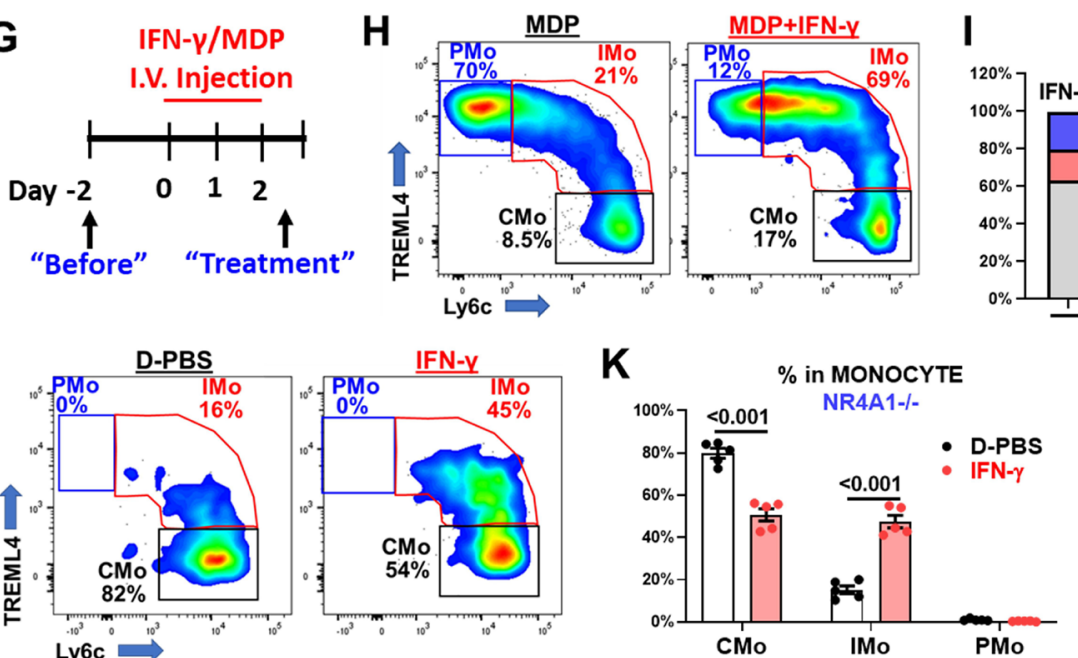

\%in total Monocyte IFN- $\mathrm{Y}+$
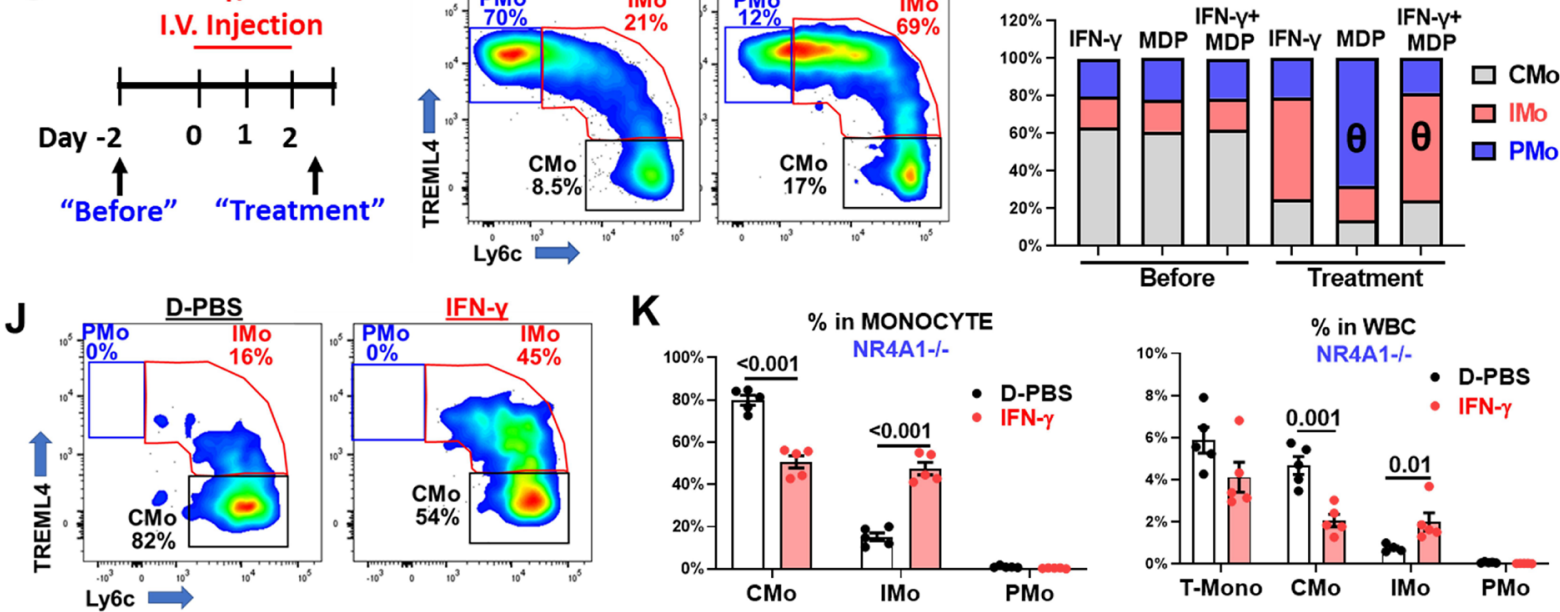

Figure 1 (A) Gating strategy for human CMo/IMo/PMo in the PBMC. (B) The expression of monocyte markers on CMo/ IMo/PMo were analyzed by flow cytometry. (C) Human monocytes were cultured with cytokines for 3 days, and expression levels change of markers analyzed by flow cytometry and shown as a heatmap (Red: increase, Purple: decrease). (D) Human monocytes were cultured with different doses of IFN- $\gamma$ for 3 days and the fold change in the levels of markers as analyzed by flow cytometry. (E) C57BL/6 mice were treated with D-PBS or IFN- $\gamma$ for 3 days, and the frequency of CMo/IMo/PMo in the blood were analyzed by flow cytometry. $(\mathrm{F})$ The column figure depicts the CMo, IMo and PMo frequency in blood in total monocytes and WBCs in D-PBS and IFN- $\gamma$ treated mice groups. (G) C57BL/6 mice were treated with IFN- $\gamma$, MDP or MDP plus IFN- $\gamma$ for 3 days. Blood samples were harvested 2 days before treatment: 'before', just after treatment: 'treatment'. $(\mathrm{H}) \mathrm{The} \mathrm{CMo} / \mathrm{IMo} /$ PMo profile in blood were analyzed, and the column figures show the frequency of IMo/PMo (I) in IFN- $\gamma$, MDP and MDP plus IFN- $\gamma$ mice group at the 'before', 'treatment' time points. (J) NR4A1-/- mice were treated with IFN- $\gamma$ as described for C57BL/6 mice. The $\mathrm{CMo} / \mathrm{IMo} / \mathrm{PMo}$ profile in blood were analyzed by flow cytometry. (K)The column figure shows the frequency of $\mathrm{CMo} /$ $\mathrm{IMo} / \mathrm{PMo}$ in the blood total monocytes and WBCs. Data represent means $\pm S E M$. ${ }^{*} \mathrm{P}<0.05$ vs control group. $\Theta p<0.01 \mathrm{MDP}$ vs IFN- $\gamma+$ MDP. CMo, classical monocytes; D-PBS: Dulbecco's phosphate-buffered saline; FSC, forward scatter; IMo, intermediate monocyte; MDP, muramyl dipeptide; MFI, mean fluorecent intensity; PBMC, peripheral blood mononuclear cell; PMo, patrolling monocyte; SSC, side scatter; WBC, white blood cell. 

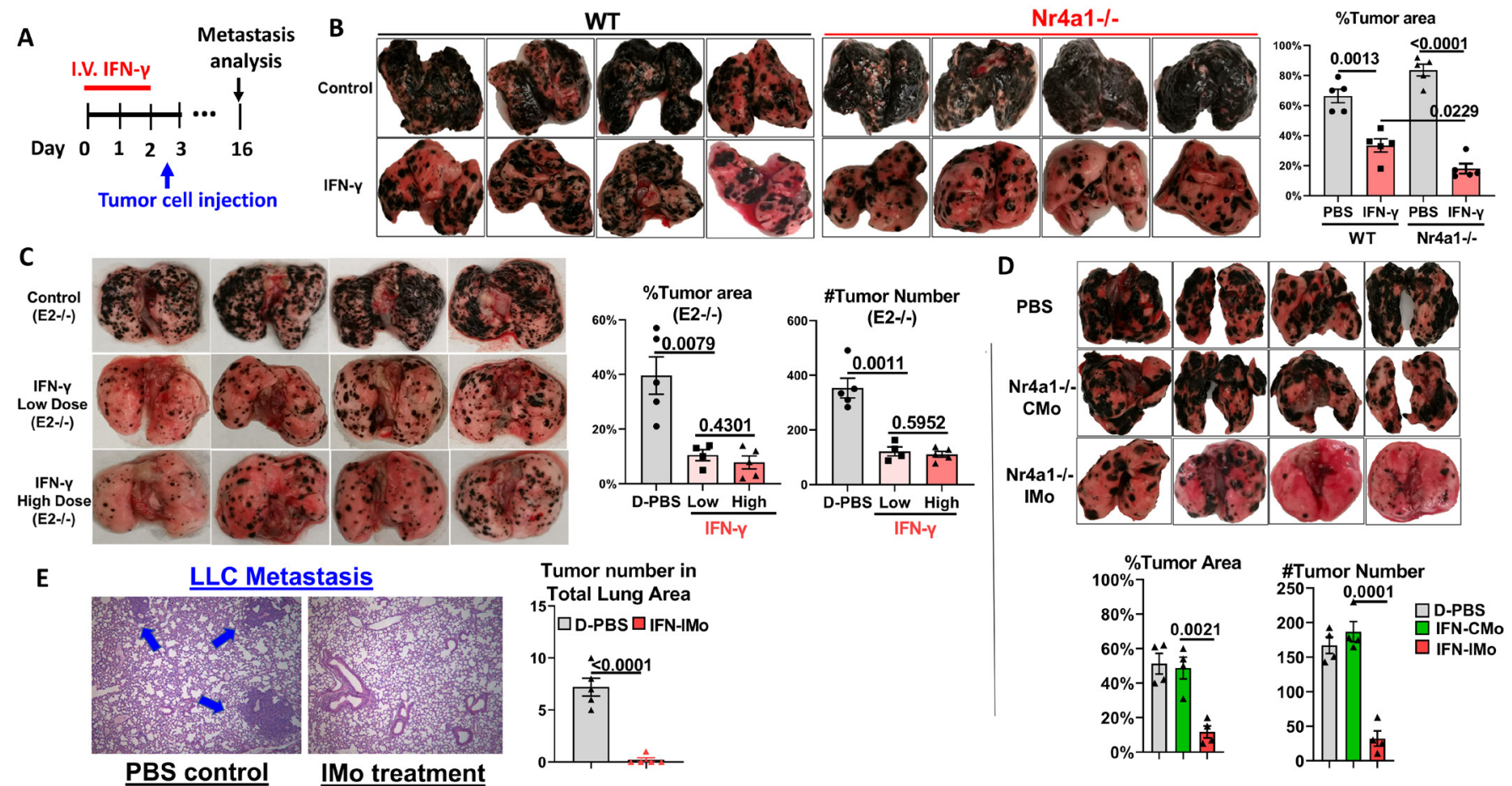

PBS control
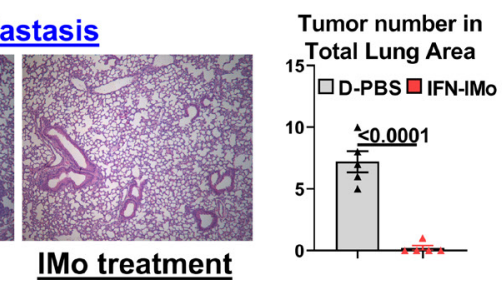

Figure 2 (A) Mice were treated with IFN- $\gamma\left(2.5 \mu \mathrm{g} /\right.$ mouse) for 3 days as described before, and tumor cells $\left(5 \times 10^{5} / \mathrm{mice}\right)$ were intravenous injected to mice after IFN- $\gamma$ treatment. The lung cancer metastasis was analyzed at day 16 (14 days after tumor injection). (B) The lung melanoma metastasis of C57BL/6 and NR4A1-/- mice with/without IFN- $\gamma$ treatment was analyzed by measuring percentage of tumor area on the lung surface. (C) The lung melanoma metastasis of E2-/- mice treated with D-PBS, low dose IFN- $\gamma(1 \mu \mathrm{g} / \mathrm{mouse})$ or high dose IFN- $\gamma(2.5 \mu \mathrm{g} / \mathrm{mouse})$ treatment was analyzed. (D) The CMo and IMo were isolated from IFN- $\gamma$ treated NR4A1-/- mice $\left(1 \mu \mathrm{g} /\right.$ mouse, 3 days) and adoptively transferred into NR4A1-/- mice $\left(1 \times 10^{5} / \mathrm{mice}\right)$ along with B16F10 $\left(5 \times 10^{5} / \mathrm{mice}\right)$ cell. Lung metastasis was analyzed 14 days after tumor cell injection. (E) The IMo were isolated from IFN- $\gamma$ treated E2-/- mice (1 $\mathrm{\mu g} /$ mouse, 3 days) and adoptively transfer into E2-/- mice along with Lewis cancer cell $\left(5 \times 10^{5} / \mathrm{mice}\right)$, and lung metastasis was analyzed 14 days after tumor cell injection. Data represent means \pm SEM. CMo, classical monocytes; IMo, intermediate monocyte; PBS, phosphate-buffered saline; WT, wildtype mice.

in WT mice (figure 1J,K), indicating that IFN- $\gamma$ enhances CMo to IMo differentiation in addition to blocking IMo to PMo differentiation. The data also support the notion that NR4A1, a key transcription factor for PMo differentiation, is dispensable for IFN- $\gamma$ driven IMo expansion.

Altogether, these results indicate that IFN- $\gamma$ can induce IMo expansion by enhancing CMo to IMo differentiation and blocking IMo differentiation.

\section{IMo differentiation, but not PMo differentiation, is pivotal for inhibition of cancer metastasis by IFN- $\gamma$}

PMo was shown to inhibit metastatic lung cancer through patrolling the endothelium of blood vessels. ${ }^{6} 724$ Whether IMo, a cell type without patrolling function, ${ }^{6}$ can also inhibit tumor lung metastasis is not known. To test this, mice were intravenous injected with IFN- $\gamma$ as described before for 3 days to induce IMo expansion, followed by injection of tumor cells (B16F10 and Lewis cells, $5 \times 10^{5} /$ mouse) 1 day after IFN- $\gamma$ treatment. Analysis at day 16 (figure 2A) revealed inhibition of melanoma lung metastasis in WT (wild-type) mice by $\sim 50 \%$ following IFN- $\gamma$ treatment (figure $2 \mathrm{~B}$ ) in the WT mice. Because IFN-IMo can develop into PMo in the absence of IFN- $\gamma$ (online supplemental figure S1D) and IFN-IMo may inhibit cancer metastasis after differentiating into PMo, we also tested the effect of IFN- $\gamma$ in NR4A1-/-mice which lack PMo even in the presence of IFN- $\gamma$ (figure 1J). Surprizing, the antimetastatic effect of IFN- $\gamma$ treatment was far greater in NR4A1 mice $(80 \%$ decrease in tumor area, figure 2B) compared with WT mice (50\% decrease). NR4A1, in addition to its role in monocytes, also modulates macrophage function. ${ }^{25}$ To rule out the unspecific effects of total NR4A1 deficiency, we tested the effect of high dose $(2.5 \mu \mathrm{g} / \mathrm{mouse}$, the dose used before) and low dose $(1 \mu \mathrm{g} /$ mouse) IFN- $\gamma$ treatment in E2-/- mice which lack NR4A1 only in monocytes but not macrophages. ${ }^{5}$ Both high and low dose IFN- $\gamma$ inhibited melanoma lung metastasis in E2-/mice (figure 2C). The efficiency of IFN- $\gamma$ inhibiting tumor seeding (69\% decrease in metastatic melanoma) is close to its overall antimetastasis effect $(81 \%$ decrease in metastatic melanoma area), indicating that the antimetastasis effect of IFN- $\gamma$ treatment is mediated mostly through preventing seeding and to a lesser extent through reducing tumor growth. No statistical differences were found in the inhibition of cancer metastasis or IMo expansion between high and low dose of IFN- $\gamma$ (online supplemental figure S2A). The IFN- $\gamma$ dose of $1 \mu \mathrm{g} /$ mouse was used for the all the next set of studies. These data indicate that PMo differentiation 
is dispensable for the anti-metastasis effect of IFN- $\gamma$. In addition, we analyzed the iNOS and ARG1 expression in the lung monocyte/macrophage subsets and found no difference between phosphate-buffered saline (PBS) and IFN- $\gamma$ treated mice (online supplemental figure S2B), suggesting that the antimetastasis effect of IFN- $\gamma$ treatment is not mediated through induction of M1 macrophage/monocyte phenotype.

To distinguish whether IMo differentiation is required for IFN- $\gamma$ driven inhibition of cancer metastasis by monocytes, purified CMos (IFN-CMos) or IMos (IFN-IMos) from IFN- $\gamma$ treated NR4A1-/- mice (figure $1 \mathrm{~J}$ ) were adoptively transferred $\left(1 \times 10^{5}\right.$ cell/mouse $)$ into NR4A1-/- mice (to limit interference from PMo) along with B16F10 cells $\left(5 \times 10^{5} \mathrm{cell} / \mathrm{mouse}\right)$. Analysis 14 days later revealed that melanoma lung metastasis was effectively inhibited in mice adoptively transferred with IFN-IMo but not IFNCMo (figure 2D, 78\% inhibition by IMo compared with control groups). These data demonstrated the potent antimetastasis activity of IFN-IMo. We found that metastatic tumor number was inhibited by $81 \%$ and the area of metastatic melanomas by $78 \%$, indicating that prevention of seeding is the more dominant effect of IFN-IMo. These data also indicate that activation by IFN- $\gamma$ in monocytes alone is not sufficient to confer antitumor metastasis properties, but that differentiation to IMo is critical for monocyte-mediated inhibition of tumor metastasis following IFN- $\gamma$ treatment. The antimetastasis effect of IFN-IMo from E2-/- mice was further confirmed using the LLC metastasis model (figure 2E). Because of the extremely low numbers, control IMos (without IFN- $\gamma$ treatment) were not analyzed in this study.

We next attempted to examine the fate of E2-/- IFNIMo which lack ability to differentiate into PMo, we transferred purified E2-/- IFN-IMo $\left(1 \times 10^{6} /\right.$ mouse, CD 45.2 background) to CD45.1 mice and analyzed recipient myeloid cell populations in the blood, lung, and spleen 3 days later. While very few CD45.2 IMo remained in the blood, no CD45.2 positive cells were detected in the lung or spleen from CD45.1 recipient mice. Although we were unable to determine the fate of E2-/- IFN-IMo, these data suggest that the inhibitory effect of IFN-IMos from E2-/mice on cancer lung metastasis is unlikely to be mediated through differentiation into long-lasting monocyte/ macrophage/dendritic cells in the lung or inside tumors. Altogether, these data indicates that IMo is the pivotal monocyte subset for IFN- $\gamma$ mediated inhibition of cancer metastasis through monocyte.

\section{IFN-IMos induce NK cell expansion and promote NK cell differentiation and activation}

Since relatively low numbers IFN-IMos $\left(1 \times 10^{5} /\right.$ mouse) were able to inhibit melanoma (B16F10 cells, $5 \times 10^{5} /$ mouse) lung metastasis, it was deemed unlikely that IFN-IMo can exert a direct cytotoxic effect on tumor cells. To determine whether IFN-IMo anti-metastasis effect was mediated through other immune cells, we analyzed the immune cell profiles of peripheral blood and lungs of mice at 3 days after
B16F10 injection (mice were pretreated with IFN- $\gamma$ or PBS as described before) using mass cytometry (CyTOF, Fluidigm). The data were analyzed using t-distributed stochastic neighbor embedding ( $t-\mathrm{SNE}$ ). The t-SNE analysis automatedly separates WBC into 21 cell clusters based on 16 marker expressions (figure 3A,B, online supplemental table $\mathrm{S} 1$ ). Cluster 2 in blood and lung were robustly increased in IFN- $\gamma$ treated group (figure 3A,B, pointed out by red arrow). Cell marker expression analysis revealed that cluster 2 in both blood and lung were NK cells (NK1.1+TCR-B-B220Gr-1- cells, figure 3C, green color indicating high expression). Cluster 1 which comprises CD8 +CD62L+CD44+cells (online supplemental table S1), was also increased in blood samples from IFN- $\gamma$ group, although these same cells were not increased in IFN- $\gamma$ group in the lung (cluster 16 in lung samples). These data were confirmed using classic flow cytometry analysis (figure 3D) which showed 2.5-3 fold increase in NK cell (CD3-NK1.1+cell) number/frequency in the blood and lung after IFN- $\gamma$ treatment. Analysis of CD4+, and CD8 + T cells and their subsets in lung samples with/ without IFN- $\gamma$ treatment (online supplemental figure S3A,B) did not reveal any significant changes. We also found higher NKT cell $(\mathrm{CD} 3+\mathrm{NK} 1.1+)$ frequency/number in the IFN- $\gamma$ group although at much lower levels than NK cells (online supplemental figure S3C). While our finding that short term IFN- $\gamma$ treatment induces NK cell expansion is different from previous studies showing that IFN- $\gamma$ is mostly not essential for NK cell development ${ }^{26}$ and that chronic exposure to IFN- $\gamma$ inhibits NK cell development, ${ }^{27}{ }^{28}$ it is supported by reports that IFN- $\gamma$ can accumulate and activate NK cells in tumors. $^{29} 30$

Based on the peripheral NK cell maturation markers, CD27 and CD11b that defines immature (CD27-CD11b-) and terminally differentiated CD27-CD11b+NK cells ${ }^{31}$ (figure 3E), we found that IFN- $\gamma$ treatment significantly increased the terminal CD27-CD11b+NK cells within NK populations in both blood and lung. Inhibitory receptor NKG2A and activating receptor LY49D expression levels on NK cells were not affected by IFN- $\gamma$ treatment in vivo (online supplemental figure S3D), but analysis of CD107a, is a cytotoxic marker on NK cells revealed higher CD107 +NKcell frequencies in the lung after IFN- $\gamma$ treatment, suggesting that IFN- $\gamma$ increases cytotoxic activity of NK cells (figure 3F) (the CD107 +frequency in blood NK cell was extremely low $(<1 \%)$ with no differences between PBS and IFN- $\gamma$ groups, data not shown).

We compared the pro-NK cell activity of IFN- $\gamma$ treatment in the control mice and E2-/- mice at the differentiation time point. The change in NK cell frequency peaked at day four and was back to normal levels at day 13 after IFN- $\gamma$ treatment, and the NK cell expansion induced by IFN- $\gamma$ treatment was significantly stronger in the E2-/ mice (figure 3G). These data indicate that NR4A1 in monocyte inhibits the pro-NK cell activity of IFN- $\gamma$.

To directly test the effect of IFN-IMo on NK cell expansion, we adoptively transferred IFN-CMo and IFN-IMo $\left(1 \times 10^{5} /\right.$ mouse) from IFN- $\gamma$ treated NR4A1-/- (figure $\left.3 \mathrm{H}\right)$ 

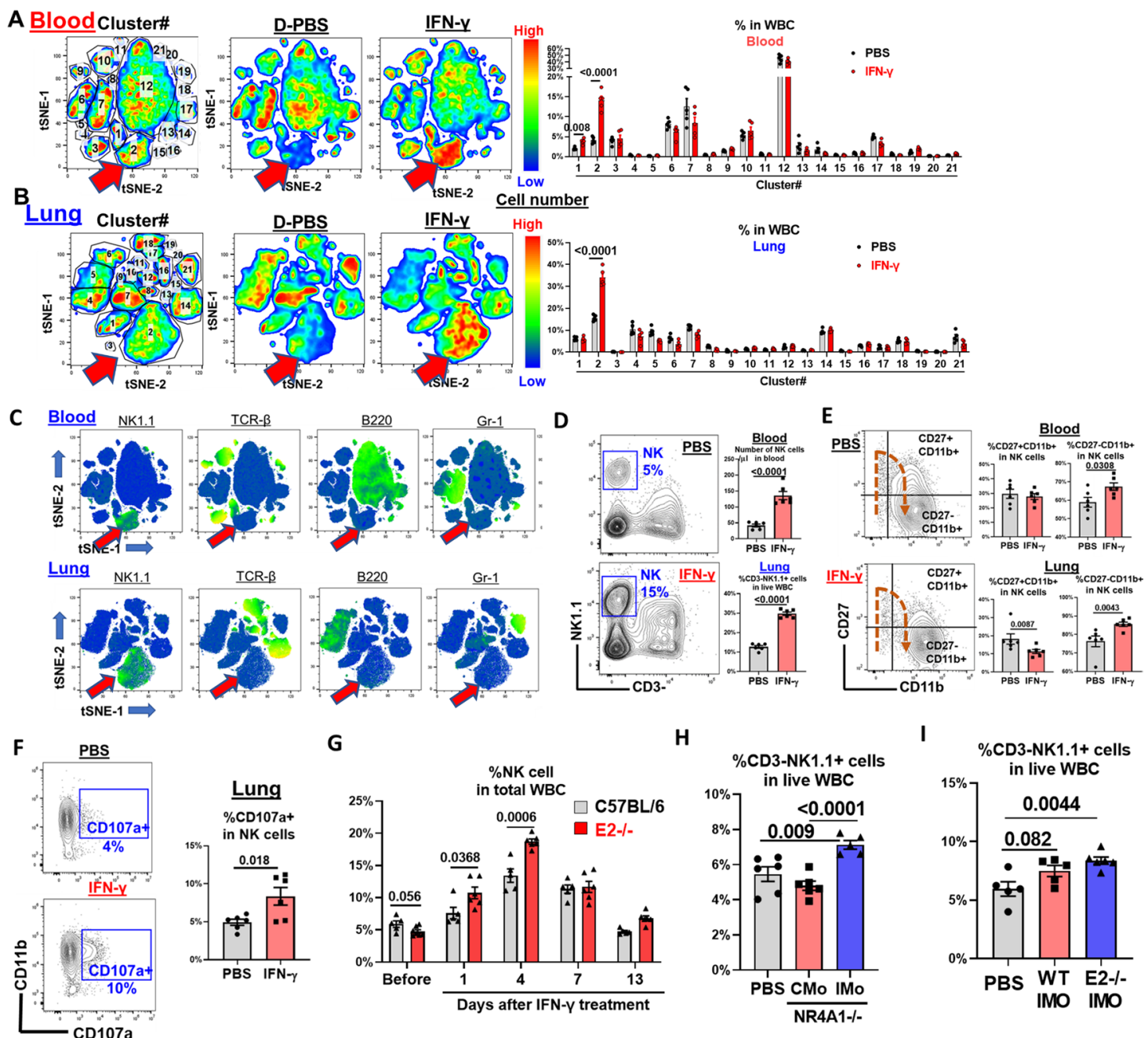

G

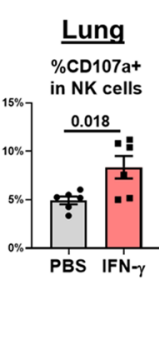

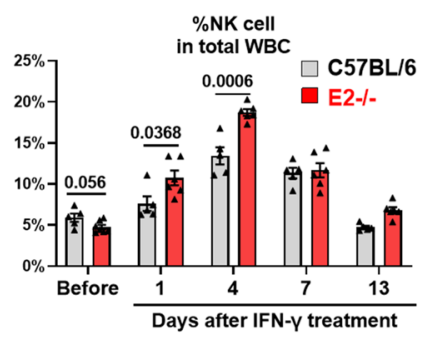

H

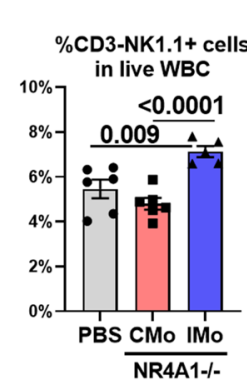

Figure 3 C57BL/6 mice were treated with PBS or IFN- $\gamma$ for 3 days followed by B16F10 cell intravenous injection as described before. Three days after tumor cell injection, blood and lungs were harvested, and the immune cell profile of samples were analyzed by CytoF. The result of CytoF was analyzed using tSNE method to automatically separate WBCs into different cell clusters based on marker expression levels. (A, B) The pseudo color figure showed the location and cell number of different cell clusters in blood and lung samples from D-PBS and IFN- $\gamma$ groups and the frequency of cell clusters was compared between D-PBS and IFN- $\gamma$ groups (The location of cluster two was pointed out by red arrow). (C) The expression of NK1.1, TCR- $\beta$, B220, and Gr-1 on different cell subsets were exhibited to show the location of NK/NKT cell, T cell, B cell, and neutrophil/monocyte location in tSNE. (D-F) C57BL/6 mice were treated as in the (A) 3 days after tumor cell injection, blood and lung were harvested, and the NK cell profile was analyzed by classic flow cytometry. (G) C57BL/6 and E2-/- mice were treated with IFN- $\gamma$ for 3 days as described before, NK cell frequency in the blood was analyzed by flow cytometry 2 days before the treatment and at 1,4 , 7, and 13 days after treatment. $(\mathrm{H}) \mathrm{CMo}$ and IMo from IFN- $\gamma$ treated NR4A1-/- mice were transferred into C57BL/7 mice as described before, and the NK cell frequency was analyzed 3 days after adoptive transfer. (I) IMo from IFN- $\gamma$ treated C57BL/6 or E2-/- mice were transferred into C57BL/7 mice as described before, and the NK cell frequency was analyzed 3 days after adoptive transfer. Data represent mean \pm SEM. CMo, classical monocytes; IMo, intermediate monocyte; PBS, phosphatebuffered saline; t-SNE, t-distributed stochastic neighbor embedding; WBC, white blood cell.

or IMo from either IFN- $\gamma$ treated control mice or E2-/mice to WT mice (figure 3I). NK cell frequency was increased in IFN-IMo but not IFN-CMo transferred mice 3 days post- transfer (figure $3 \mathrm{H}$ ). The increase in NK frequency after E2-/- IFN-IMo transfer compared with WT IFN-IMo transfer (figure 3I) may in part be responsible for higher anti-metastasis activity of IFN- $\gamma$ in NR4A1-/mice compared with WT mice (figure 2B).

Altogether, these data support the conclusion that IFN-IMo induced by short term IFN- $\gamma$ treatment can induce NK cell expansion and promote peripheral NK cell differentiation and activation and that NR4A1 in monocyte inhibits the pro-NK cell activity of IFN- $\gamma$.

\section{IFN-IMo induces NK cell expansion through IL-27 and NK cell associated chemokines}

Chemokines play a critical role in immune cell co-localization and interaction. To test whether IFN- $\gamma$ increases NK cell-associated chemokine production, we first examined levels of chemokines in the supernatants of IFN- $\gamma$ treated human monocytes and found an increase in CCL2, CXCL9 and CXCL10 production (figure 4A). 

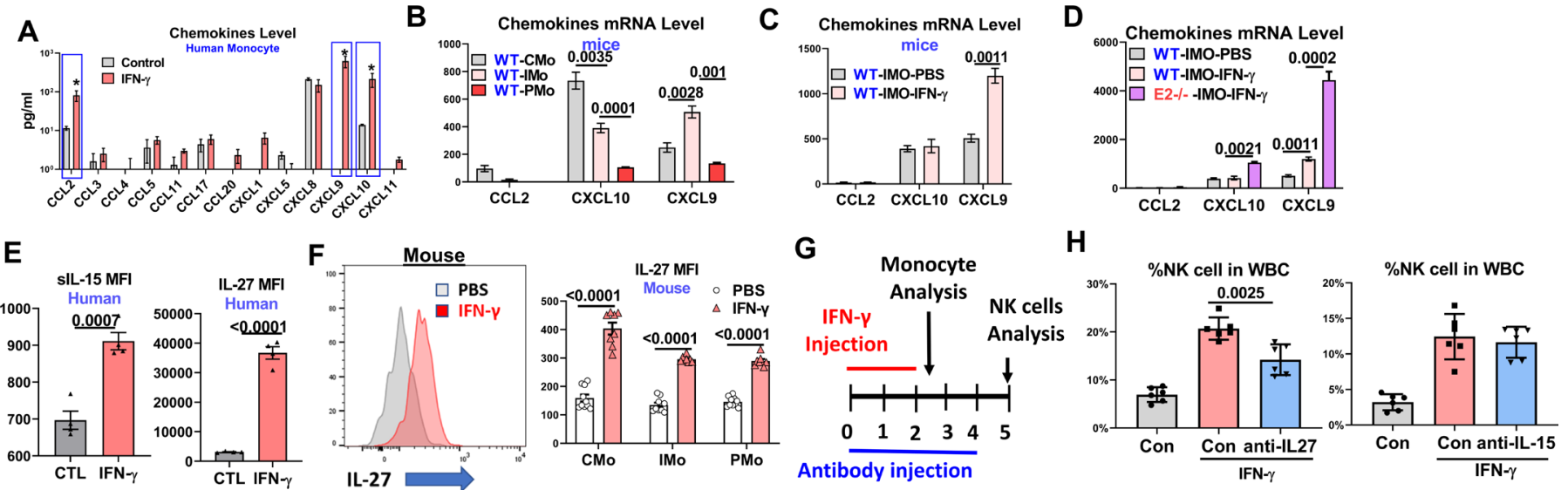

Figure 4 (A) Human monocytes were cultured with IFN- $\gamma$ for 3 days, the chemokine levels in the culture medium were analyzed by Legendplex kit. (B-D) CMo, IMo, and PMo from D-PBS, IFN- $\gamma$ treated C57BL/6 mice and IFN- $\gamma$ treated E2-/- mice was sortpurified, and mRNA sequencing was used to analyze the mRNA levels of CCL2 and CXCL9/10 in the monocyte subsets. Data represent means \pm SEM. (E) Human monocytes were cultured for 3 days with IFN- $\gamma(5 \mathrm{ng} / \mathrm{mL})$, and sIL-15 and IL-27 expression was analyzed by flow cytometry and shown as mean fluorescence intension (MFI). (F) Mice were treated with IFN- $\gamma$ as described before and IL-27 expression in monocyte subsets were analyzed by flow cytometry. The histogram shows IL-27 MFI difference in IMo between PBS group and IFN- $\gamma$ group. The column figure shows IL-27 MFI in IMo in PBS and IFN- $\gamma$ mice group.

(G) C57BL/6 mice were treated with IFN- $\gamma$ for 3 days as described before. Neutralizing antibodies ( $20 \mu \mathrm{g} / \mathrm{mice} / \mathrm{day}) \mathrm{were}$ injected for 5 days (day $0-4$ ) to block the activity of cytokines. Blood samples were harvested at day four for monocyte analysis and day five for NK cell analysis. $(\mathrm{H})$ Mice were treated as described in (G), the NK cell frequency in the blood (day 5) was analyzed. Data represent means \pm SEM. CMo, classical monocytes; IMo, intermediate monocyte; MFI, mean fluorescent intensity; PBS, phosphate-buffered saline; PMo, patrolling monocyte; WBC, white blood cell; WT, wild-type mice.

Since all these three chemokines are important in NK cell recruitment, ${ }^{32} 33$ we analyzed CCL2, CXCL9/10 mRNA levels in purified mouse blood/spleen CMo, IMo and PMo by RNA sequencing (more details in Materials). Only CXCL9 transcript was higher in IMo (figure 4B). RNA sequencing of purified IMo from PBS or IFN- $\gamma$ treated mice showed an increase in CXCL9 but not CCL2 and CXCL10 transcripts in IMo from IFN- $\gamma$ treated mice (figure 4C). These data indicate that CXCL9 may be a key chemokine for IFN-IMo recruitment of NK cells in both human and mice. Higher levels of CXCL9 (fourfold) and CXCL10 (twofold) transcripts were also detected in E2-/mice (figure 4D), which may partly explain the higher numbers of expanded NK cells by IFN-IMo from E2-/- as compared with WT mice (figure $3 \mathrm{H}$ ). Altogether, our data suggest that IFN-IMo recruits NK cells through CXCL9.

Monocyte/macrophages can promote NK cell development and differentiation through cytokines including IL-15 ${ }^{34}$ and IL-27. ${ }^{35}$ To identify key cytokines responsible for IFN-IMo mediated NK cell expansion, we first analyzed the change in IL-15 expressed on the cell surface (sIL15), important for IL-15 trans-presentation, ${ }^{34}$ as well as intracellular IL-27 levels in human and mouse monocytes after IFN- $\gamma$ treatment both in vitro and in vivo. We found a 12-fold increase in IL-27 and a $31 \%$ increase in sIL-15 on IFN- $\gamma$ treated human monocytes compared with control (figure $4 \mathrm{E}$ ). In vivo, we detected a significant increase in IL-27 expression in CMo/IMo/PMo of IFN- $\gamma$ treated mice compared with the control group (figure $4 \mathrm{~F}$ ) but were unable to detect IL-27 in plasma even after IFN- $\gamma$ treatment. These data suggest that secretion of IL-27 induced by IFN- $\gamma$ is likely regulated through an as yet unknown mechanism rather than simple release into circulation. We were unable to detect sIL-15 on any monocyte subsets from either group by flow cytometry or soluble IL-15 in plasma (data not shown). To directly test the role of IL-15 and IL-27 in IFN- $\gamma$ induced IMo and NK cell expansion, we treated mice with neutralizing antibodies to IL-15 and IL-27 with IFN- $\gamma$ treatment (figure 4G). Antibody blockade of IL-27 (20 $\mu \mathrm{g}$ / mice/day, I.P. injection) had no effect on IMo expansion after IFN- $\gamma$ treatment (online supplemental figure S4) but inhibited NK cell expansion by half (figure $4 \mathrm{H}$ ). Given that adoptive transfer of IFN-IMo, but not IFN-CMo, induced NK cell expansion despite high levels of IL-27 expression by IFN-CMo, it is possible that an unknown IFN-IMo specific mechanism controls IL-27 release to induce NK cell expansion. Interestingly, we did not find any significant effect of IL-15 blockade $(20 \mu \mathrm{g} / \mathrm{mice} /$ day, I.P. injection) on IMo expansion and NK cell expansion after IFN- $\gamma$ treatment (figure $4 \mathrm{H}$ ).

These data support a role for IL-27 as a critical cytokine for IFN-IMo mediated NK cell expansion.

\section{IFN- $\gamma$-STAT1 canonical pathway is dispensable for IFN- $\gamma$ inducing IL-27 expression in IMo}

IFN- $\gamma$ mediates its function majorly through STAT1 canonical pathway. ${ }^{36}$ We tested the effect of IFN- $\gamma$ on monocyte subset differentiation and activity in the STAT1-/- Mice. We found that IFN- $\gamma$ treatment decreased CMo number/ frequency but also led to an increase in PMo number/ frequency $(\sim 60 \%)$ in STAT1 knockout mice (STAT1-/mice) (figure 5A,B). Since IMo numbers were not increased, these data suggest that in the absence of STAT1, IFN- $\gamma$ may promote CMo differentiation, leading 
A

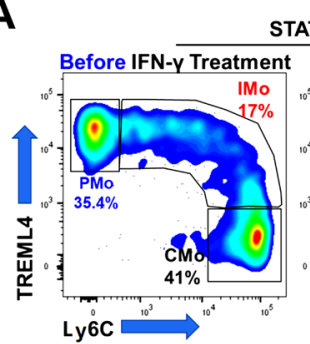

C

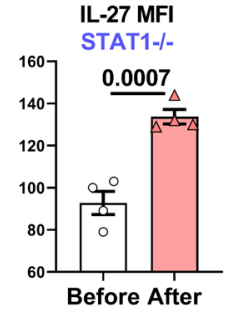

STAT1-/-

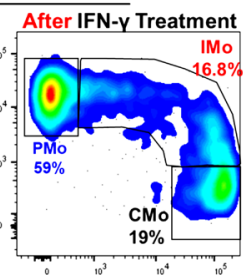

D

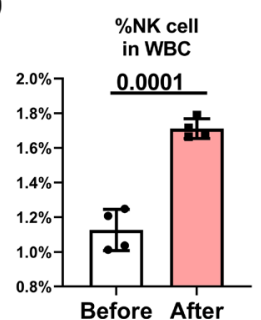

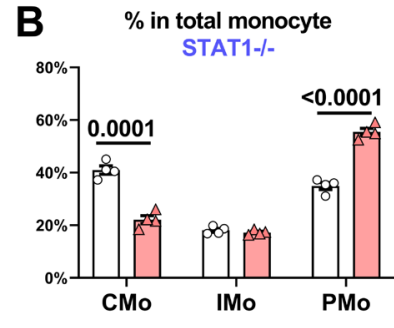

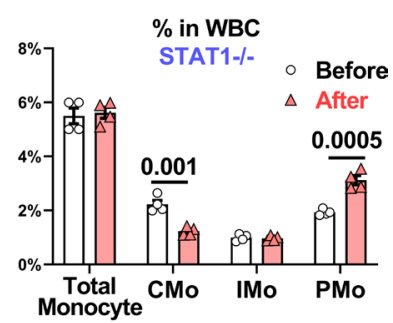

$\%$ in NK cells

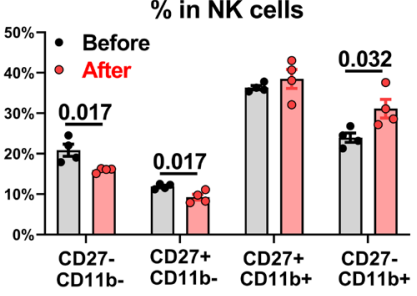

Figure 5 (A) STAT1-/- mice were treated with IFN- $\gamma$ for 3 days as described before, and the frequency of monocyte and its subsets were analyzed by flow cytometry as described in figure 1. (B) The column figure shows the frequency of CMo/IMo/PMo in the blood total monocytes and WBCs before and after IFN- $\gamma$ treatment. (C) STAT1-/- mice were treated with IFN- $\gamma$ for 3 days and IL-27 expression in blood monocyte subsets before and after IFN- $\gamma$ treatment were analyzed by flow cytometry. (D) STAT1/- mice were treated with IFN- $\gamma$ for 3 days as described before, and peripheral blood NK cell and its subsets frequency before IFN- $\gamma$ treatment and 3 days after IFN- $\gamma$ treatment were analyzed by flow cytometry. Data represent means $\pm \mathrm{SEM}$. CMo, classical monocytes; IMo, intermediate monocyte; MFI, mean fluorescent intensity; NK, natural killer cell; PMo, patrolling monocyte; WBC, white blood cell.

to a decrease in CMo numbers, but that it is no longer able to block further differentiation of IMo into PMo. These data indicate that STAT1 is a critical transcription factor controlling inhibition of IMo to PMo differentiation by IFN- $\gamma$, but the mechanism of IFN- $\gamma$ mediated increase in CMo to IMo differentiation remains unclear.

We also tested the effect of IFN- $\gamma$ mediated induction of IL-27 expression and NK cell expansion in STAT1-/mice. Surprisingly, we found that STAT1 is indispensable for IFN- $\gamma$ driven increase in IL-27 expression in IMo (figure 5C). In addition, we found that IFN- $\gamma$ induced NK cell expansion in STAT1-/- mice although the fold increase (1.5-fold) is lower than WT mice (threefold) may due to lack of IMo expansion in IFN- $\gamma$ treated STAT1-/mice. Increased NK peripheral differentiation (lower CD11b- NK, and higher CD27-CD11b+NK frequency) was also found in IFN- $\gamma$ treated STAT1-/- mice, indicating that IFN- $\gamma$-STAT1 canonical pathway is dispensable for NK cell activation by IFN- $\gamma$ (figure 5D). These data suggest that IFN- $\gamma$ STAT1-independent non-canonical pathway is critical for increased IMo activity by IFN- $\gamma$.

Altogether, our data support a critical role for IFN- $\gamma$ non-canonical pathway in IFN-IMo-mediated induction of NK cell expansion through IL-27.

\section{F0X01 in IFN- $\gamma$ non-canonical pathway is critical for the activity of IFN-IMo}

Our data (figure 5C,D) supports a role for non-canonical pathway as critical for IFN- $\gamma$ driven monocyte IL-27 expression. To determine the key signaling molecules in this pathway, we screened a number of IFN- $\gamma$ non-canonical pathway signaling molecules by using specific inhibitors and found blocking PI3K/AKT and p38/MAKPK pathways, but not NF-KB pathway, inhibited the effect of IFN- $\gamma$ inducing IL-27 in human monocyte (online supplemental figure S5A) (The data using STAT1 inhibitors are not included due to their potent cytotoxicity against monocytes in the presence of IFN- $\gamma$ ). FOXO1 is a transcription factor downstream from both AKT and p38, but whether it is involved in IFN- $\gamma$ non-canonical pathway is not known. We found that IFN- $\gamma$ dose-dependently induced FOXO1 expression in human monocytes (figure $6 \mathrm{~A}, \mathrm{~B}, \sim 10$-fold increasing at $5 \mu \mathrm{g} / \mathrm{mL}$ ) as determined by flow cytometry and western blot analysis (online supplemental figure S5B). PI3K/AKT and P38 inhibitors, but not NF-KB inhibitor, prevented the induction of FOXO1 by IFN- $\gamma$ (online supplemental figure S5C), suggesting that FOXO1 is downstream from PI3K/AKT and p38, consistent with previous reports. ${ }^{37} 38$ Using FOXO1 inhibitor (FOXO1-B, AS1842856), we found that FOXO1-B inhibited IFN- $\gamma$ driven IL-27 upregulation (65\% inhibition, figure $6 \mathrm{C}$ ). These results suggest that FOXO1 is critical for IFN- $\gamma$ induction of IL-27 expression in human monocyte through IFN- $\gamma$ non-canonical pathway.

To characterize the role of FOXO1 in vivo, we analyzed FOXO1 expression levels in mouse blood monocyte subsets before and after IFN- $\gamma$ treatment. Highest FOXO1 expression was detected in IMo as compared with CMo and PMo (figure 6D), suggesting that FOXO1 expression may change during monocyte subset differentiation. We also found intravenous injection of IFN- $\gamma$ led to an increase of FOXO1 expression in CMo and IMo (figure 6E) although the change was mild compared with in vitro treated 

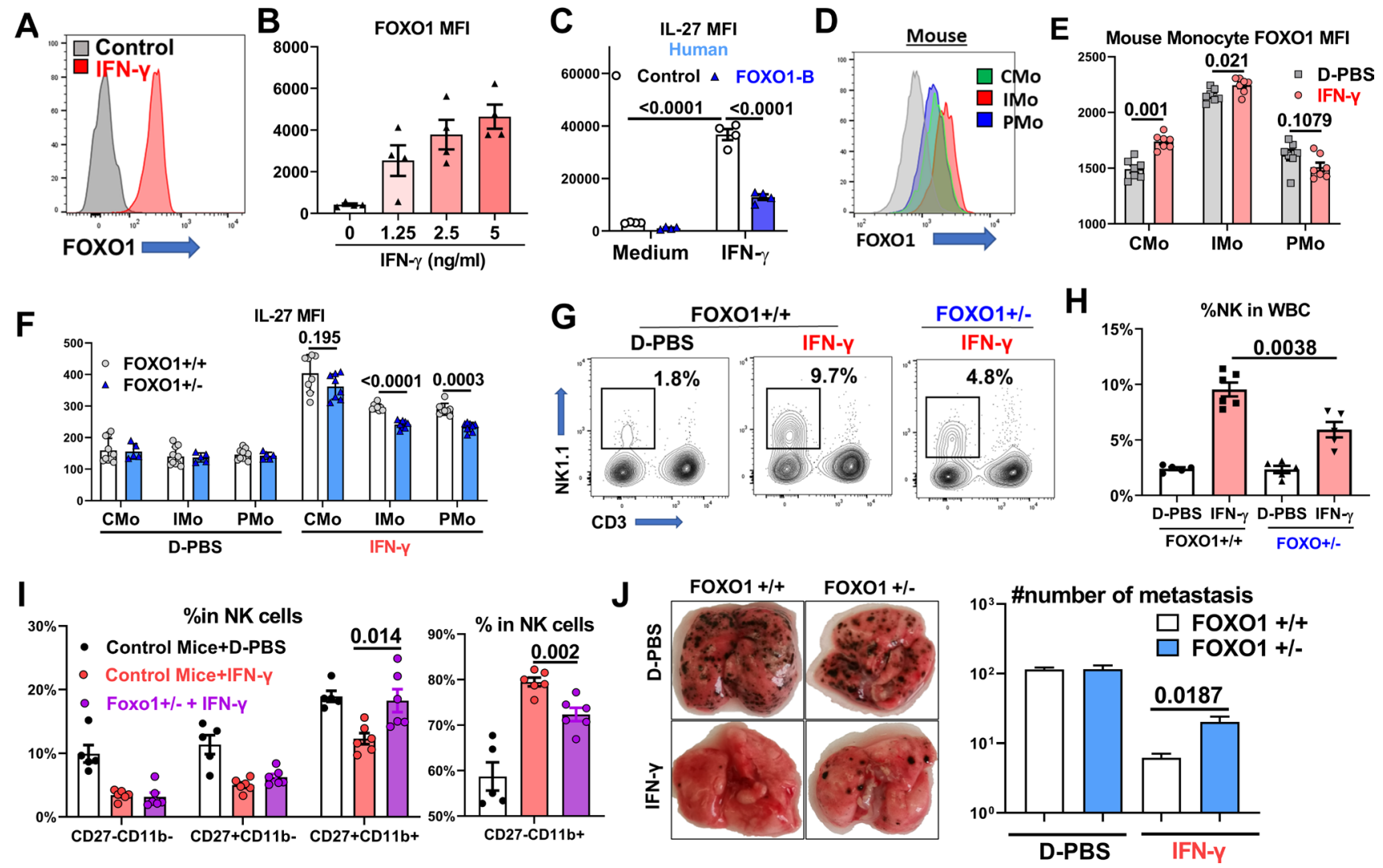

Figure 6 (A) Human monocytes were cultured with $10 \mathrm{ng} / \mathrm{mL}$ IFN- $\gamma$ for 3 days, and FOXO1 expression level in monocytes was analyzed by flow cytometry. (B) Human monocytes were cultured with different concentration IFN- $\gamma$ for 3 days, FOXO1 expression level was analyzed by flow cytometry. (C) Human monocytes were cultured as in (A) in the presence of FOXO1 inhibitor, and the IL-27 levels in monocytes were analyzed by flow cytometry. (D) The histogram shows FOXO1 expression in mouse blood CMo/IMo/PMo. (E) C57BL/6 mice were treated with D-PBS or IFN- $\gamma$ for 3 days as described before. The column figure shows FOXO1 expression levels in blood CMo, IMo and PMo. (F) C57BL/6 mice were treated as in (E), IL-27 in the mice monocyte subsets was analyzed by flow cytometry. $(\mathrm{G}-\mathrm{H}) \mathrm{FOXO1+/+and} \mathrm{FOXO1 \pm mice} \mathrm{were} \mathrm{treated} \mathrm{as} \mathrm{in} \mathrm{(E).} \mathrm{The} \mathrm{NK} \mathrm{cell}$ frequency in blood was analyzed by flow cytometry at 3 days after IFN- $\gamma$ treatment. (I) Mice were treated as described in (E), the NK cell differentiation was analyzed by flow cytometry based on CD27 and CD11b expression. (J) FOXO1+/+and FOXO1 were treated as in $(\mathrm{F})$, B16F10 cell $\left(2.5 \times 10^{5} /\right.$ mice $)$ were injected into mice after IFN- $\gamma$ treatment ended. The lung metastasis was analyzed at 14 days after tumor cell injection. Data represent means \pm SEM. CMo, classical monocytes; D-PBS, Dulbecco's phophate buffered saline; IMo, intermediate monocyte; MFI, mean fluorecent intensity; NK, natural killer cell; PMo, patrolling monocyte; WBC, white blood cell.

human monocytes. We tested the effect of IFN- $\gamma$ in tamoxifen inducible myeloid specific FOXO1 knockdown mice (homozygote is unavailable in this strain, detail in the 'Methods' section). We found lower IL-27 expression in IMo from FOXO1 \pm mice compared with FOXO1+/+mice (figure 6F), indicating that FOXO1 is critical for IL-27 upregulation by IFN- $\gamma$ in IFN-IMo. We next tested its role in IFN-IMo mediated NK cell expansion. Treatment of FOXO1 \pm mice with IFN- $\gamma$ led to a drop in half in NK cell expansion relative to $\mathrm{FOXO} 1+/+$ mice (figure $6 \mathrm{G}, \mathrm{H}$ ). It should be noted that the FOXO1 \pm mice were myeloid specific FOXO1 knock-down, and therefore the FOXO1 expression in NK cells was intact. The frequency of terminally differentiated NK cell subset (CD27-CD11b+NK) in FOXO1 \pm mice was significantly lower than control mice after IFN- $\gamma$ treatment (figure 6I, red column vs purple column). Altogether, these data indicate that FOXO1 is critical for IFN- $\gamma$-driven IL-27 expression in IMo and NK cell expansion and differentiation.
We also analyzed monocyte subset differentiation in the FOXO1 \pm mouse and found lower IMo frequency and higher PMo frequency compared with FOXO1+/+mice in the absence or presence of IFN- $\gamma$ (online supplemental figure S6D). These data suggest that FOXO1 inhibits IMo differentiation into PMo and is important for IFN- $\gamma$ driven IMo expansion. The conclusion was supported by that inhibition of FOXO1 activity by FOXO1-B (oral, $100 \mathrm{mg} / \mathrm{kg}$ body weight) during IFN- $\gamma$ treatment in mice inhibited IMo expansion induced by IFN- $\gamma$ but increased PMo frequency (online supplemental figure S5E).

Finally, we compared the effect of IFN- $\gamma$ on lung metastasis in $\mathrm{FOXO} 1+/+$ and $\mathrm{FOXO} 1 \pm$ mice. We found lower antimetastasis activity in IFN- $\gamma$ treated $\mathrm{FOXO} 1 \pm$ mice (75\% inhibition) compared with FOXO1+/+mice $(95 \%$ inhibition) although similar levels of tumor metastasis were detected in two mouse strains in the absence of IFN- $\gamma$ (figure 6J). 
Overall, these data support a critical role of FOXO1 in IFN-IMo mediated inhibition of cancer metastasis driven by upregulation of IL-27 production and NK cell expansion as well as for the induction of IFN-IMo.

\section{DISCUSSION}

In this study, we unveiled the potent anti-metastasis of IFN-IMo and identified the mechanism that controls IFN-IMo differentiation and function. To the best of our knowledge, our study is the first study to identify (1) the potent antimetastasis and pro-NK cell activity of IFNIMo; (2) FOXO1 as a key molecule for IFN- $\gamma$ inducing NK cell expansion through IL-27; (3) NR4A1 as an inhibitory molecule for IMo function. Our study has not only unveiled novel activities and mechanism of a classical antitumor cytokine but also provided potential therapeutic target for improving IFN- $\gamma$ treatment and developing monocytic cell therapy for cancer metastasis.

Compared with macrophage and dendritic cells, large numbers of monocytes are present in the blood stream which, as part of the circulatory system, play a key role for metastasis of tumor cells. PMos have been shown to prevent cancer metastasis under basal condition. ${ }^{7}$ But we found a stronger anti-metastasis effect of IFN- $\gamma$ in PModeficient mice compared with control mice. In addition, IFN-IMo from PMo deficient mice prevented cancer metastasis more effectively. These data support a role for IFN-IMos in the inhibition of cancer metastasis independent from PMo. Interestingly, although both IMos and CMos were activated in IFN- $\gamma$ treated mice, only IFN-IMo exhibited antimetastasis activity, suggesting that simply culturing human monocytes with IFN- $\gamma$ in vitro will be unlikely to provide an effective cell therapy product against cancer metastasis. Instead, elucidating the mechanism of IFN-IMo differentiation in vivo and identifying the key molecules for IFN-IMo activity will be critical for the development of more efficacious monocytic cell therapies.

A key finding of our study is that short-term IFN- $\gamma$ treatment induces a robust (3-fold) NK cell expansion. Although IFN- $\gamma$ is also produced by NK cells and is critical for NK cell cytotoxicity, it is mostly not essential for NK cell development and differentiation. In IFN- $\gamma$ knockout mice, with the exception of the liver, no differences were detected in the number/frequency of NK cells in blood, spleen, bone marrow and lymph node. ${ }^{26}$ The Lin-CD122 +NK progenitor cells are also not affected in the bone marrow and livers of IFN- $\gamma$ knockout mice. ${ }^{26}$ In contrast, based on an IFN- $\gamma$ transgenic mouse strain ${ }^{27}$ and CD137 knockout mice, ${ }^{28}$ long-term chronic exposure to IFN- $\gamma$ inhibits NK cell development by abrogating hematopoietic stem cell (HSC) proliferation and NK cell maturation. ${ }^{27}$ In support of these studies, others have also found a robust effect of IFN- $\gamma$ on HSC development as evidenced by higher levels of SCA-1 expression on HSC $^{39}$ as in our study. Altogether, our data suggest that short-term IFN- $\gamma$ treatment can be a potential strategy for inducing NK cell expansion while avoiding the bone marrow toxicity of long term IFN- $\gamma$ treatment.

FOXO1 is critical for differentiation of many immune cells including T cells, ${ }^{40}{ }^{41} \mathrm{~B}$ cells ${ }^{42}$ and NK cells. ${ }^{41}$ Our study is the first to demonstrate that FOXO1 regulates IMo/PMo differentiation and activity. Different from our findings, increased Ly6C high CMo number/frequency was found in a myeloid specific triple FOXO (FOXO1, FOXO3a and FOXO4) knockout mice. ${ }^{43}$ This discrepancy may come from (1) FOXO3a and FOXO4 modulation of monocyte cell differentiation which is supported by higher total monocyte number/frequency in triple FOXO knockout mice but not in FOXO1 alone knockout mice $^{43}$; (2) We used a tamoxifen inducible gene knockdown system to avoid the potential interference resulting from gene knock out/down on mouse development. FOXO1 activity is modulated by various metabolismassociated factors and plays a complex role in numerous metabolic syndromes including obesity, diabetes mellitus ${ }^{44}$ and atherosclerosis. ${ }^{45}$ IMo and PMo frequencies are altered in in the patients with metabolic diseases, ${ }^{46}$ and cancer metastasis risk is higher in the cancer patients with metabolic diseases including obesity. ${ }^{47}$ Whether FOXO1 contributes to the IMo/PMo abnormality and higher cancer metastasis risk in these diseases need further study.

An interesting finding of our study is that IFN- $\gamma$-driven IMo expansion was independent of NR4A1. Furthermore, our data suggest that NR4A1 inhibits IFN-IMo activity. Compared with control mice, IFN-IMo from Nr4a1-/mouse showed stronger antimetastasis activity, promoting a more robust NK cell expansion, most likely resulting from increased NK cell associated chemokine CXCL9/10/16 expression. The mechanism for NR4A1 inhibition of IFNIMo activity is unclear. NF- $\mathrm{KB}$ signaling pathway has been shown to be activated in IMo from Nr4a1-/- mice. ${ }^{3}$ Activated $\mathrm{NF}-\mathrm{KB}$ signal can lead to an increase in chemokine expression including CXCL9/10/16. ${ }^{48}$ NR4A1 was also shown to bind and inhibit the activity of $\mathrm{FOXO}^{49}$ which we have found to be critical for IFN-IMo function. Future studies focusing on the mechanism of NR4A1 mediated inhibition of IFN-IMO activity will help to identify strategies to further improve the anti-metastasis ability of IFN-IMo and IFN- $\gamma$. In addition to NR4A1, we found that STAT1 and AKT/P38/FOXO1 pathways are critical for IMo differentiation and activity, respectively. Given that the STAT1 and AKT/P38/FOXO1 pathways are critical in the regulation of many cytokines/chemokines, our study will provide the necessary information for identifying additional key regulatory cytokines/chemokines that control IMo/PMo differentiation in the future.

We found that IFN-IMo induces NK cell expansion/ differentiation/activity by increasing its IL-27 production. It is known that monocytes enhance NK cell activity and differentiation through cytokines and surface molecules. Here, we focused on sIL-15, an essential cytokine for NK cell development, and IL-27 which promotes NK cell activation both in vivo and in vitro. To our surprise, we did not find higher sIL-15 expression on IFN-IMo 
compared with control IMo, and IL-15 blockade did not reverse the effect of IFN- $\gamma$ in mice. Instead, we found increased IL-27 levels in IFN-IMo compared with control IMo, and neutralization of IL-27 caused a 50\% inhibition of IFN- $\gamma$-mediated NK expansion. PMo has been shown to inhibit tumor metastasis through recruitment of NK cells by CCL3 $/ 4 / 5^{7}$ and switching inhibitory/stimulatory receptor expression balance on NK cells ${ }^{8}$ possibly through IL- $15^{50}$ but with no effect on NK cell differentiation and expansion. In this study, we find that IFN-IMo recruits NK cells through CXCL9 and promotes NK cell expansion and differentiation through IL-27 with no impact on inhibitory/stimulatory receptor expression on NK cells. These results highlight the role for a diverse set of molecules and the involvement of different mechanisms for monocyte subset control of NK cell activation, which need to be individually dissected.

In summary, our study has not only unveiled the key role of IMo differentiation in IFN- $\gamma$ mediated inhibition of cancer metastasis, but also has identified IFN-IMo as a potential 'monocyte therapeutic' against cancer metastasis and FOXO1 and NR4A1 as potential therapeutic targets for improving IFN- $\gamma$ treatment in cancer.

Contributors RW helped to conceive the idea, performed experiments, and analyzed the data; WB, MP and YL helped with experiments; KY helped with project supervision. $\mathrm{HZ}$ conceived the idea, designed, and interpreted data. $\mathrm{HZ}$ and $\mathrm{KY}$ wrote the manuscript with consultation and contribution from all coauthors. $\mathrm{HZ}$ is responsible for the overall content as guarantor and accepts full responsibility for the work and/or the conduct of the study, had access to the data, and controlled the decision to publish.

Funding This work was supported in part by R01 HL130139 (KY), P01 HL149626 $(\mathrm{KY})$, and Hugoton Foundation (HZ).

Competing interests None declared.

Patient consent for publication Not applicable.

Ethics approval All studies were approved by the institutional Review Boards of the New York Blood Center (NYBC).

Provenance and peer review Not commissioned; externally peer reviewed.

Data availability statement All data relevant to the study are included in the article or uploaded as online supplemental information.

Supplemental material This content has been supplied by the author(s). It has not been vetted by BMJ Publishing Group Limited (BMJ) and may not have been peer-reviewed. Any opinions or recommendations discussed are solely those of the author(s) and are not endorsed by BMJ. BMJ disclaims all liability and responsibility arising from any reliance placed on the content. Where the content includes any translated material, BMJ does not warrant the accuracy and reliability of the translations (including but not limited to local regulations, clinical guidelines, terminology, drug names and drug dosages), and is not responsible for any error and/or omissions arising from translation and adaptation or otherwise.

Open access This is an open access article distributed in accordance with the Creative Commons Attribution Non Commercial (CC BY-NC 4.0) license, which permits others to distribute, remix, adapt, build upon this work non-commercially, and license their derivative works on different terms, provided the original work is properly cited, appropriate credit is given, any changes made indicated, and the use is non-commercial. See http://creativecommons.org/licenses/by-nc/4.0/.

ORCID iD

Hui Zhong http://orcid.org/0000-0002-1933-3046

\section{REFERENCES}

1 Narasimhan PB, Marcovecchio P, Hamers AAJ, et al. Nonclassical monocytes in health and disease. Annu Rev Immunol 2019;37:439-56.

2 Guilliams M, Mildner A, Yona S. Developmental and functional heterogeneity of monocytes. Immunity 2018;49:595-613.

3 Hanna RN, Carlin LM, Hubbeling HG, et al. The transcription factor NR4A1 (Nur77) controls bone marrow differentiation and the survival of Ly6C- monocytes. Nat Immunol 2011;12:778-85.

4 Mildner A, Schönheit J, Giladi A, et al. Genomic characterization of murine monocytes reveals C/EBP $\beta$ transcription factor dependence of Ly6C- cells. Immunity 2017;46:849-62.

5 Thomas GD, Hanna RN, Vasudevan NT, et al. Deleting an Nr4a1 super-enhancer subdomain ablates Ly6 $\mathrm{C}^{\text {low }}$ monocytes while preserving macrophage gene function. Immunity 2016;45:975-87.

6 Cros J, Cagnard N, Woollard K, et al. Human CD14dim monocytes patrol and sense nucleic acids and viruses via TLR7 and TLR8 receptors. Immunity 2010;33:375-86.

7 Hanna RN, Cekic C, Sag D, et al. Patrolling monocytes control tumor metastasis to the lung. Science 2015;350:985-90.

8 Narasimhan PB, Eggert T, Zhu YP, et al. Patrolling monocytes control NK cell expression of activating and stimulatory receptors to curtail lung metastases. J Immunol 2020;204:192-8.

9 Panek CA, Bruballa AC, Pineda GE, et al. Cytokines use different intracellular mechanisms to upregulate the membrane expression of CX ${ }_{3}$ CR1 in human monocytes. Mol Immunol 2019;108:23-33.

10 Liu Y, Yang B, Ma J, et al. Interleukin-21 maintains the expression of CD16 on monocytes via the production of IL-10 by human naïve CD4+ T cells. Cell Immunol 2011;267:102-8.

11 Ruppert J, Friedrichs D, Xu H, et al. IL-4 decreases the expression of the monocyte differentiation marker CD14, paralleled by an increasing accessory potency. Immunobiology 1991;182:449-64.

12 Barlic J, Sechler JM, Murphy PM. IL-15 and IL-2 oppositely regulate expression of the chemokine receptor CX3CR1. Blood 2003;102:3494-503.

13 Nakai K, He Y-Y, Nishiyama F, et al. IL-17A induces heterogeneous macrophages, and it does not alter the effects of lipopolysaccharides on macrophage activation in the skin of mice. Sci Rep 2017;7:12473.

14 Wang H, Meng R, Li Z, et al. IL-27 induces the differentiation of Tr1like cells from human naive CD4+ T cells via the phosphorylation of STAT1 and STAT3. Immunol Lett 2011;136:21-8.

15 Jia $\mathrm{D}$, Jiang $\mathrm{H}$, Weng $\mathrm{X}$, et al. Interleukin-35 promotes macrophage survival and improves wound healing after myocardial infarction in mice. Circ Res 2019;124:1323-36.

16 Chen S, Luo D, Streit WJ, et al. TGF-beta1 upregulates CX3CR1 expression and inhibits fractalkine-stimulated signaling in rat microglia. J Neuroimmunol 2002;133:46-55.

17 Scheuerer B, Ernst M, Dürrbaum-Landmann I, et al. The CXCchemokine platelet factor 4 promotes monocyte survival and induces monocyte differentiation into macrophages. Blood 2000;95:1158-66.

18 Schenk M, Fabri M, Krutzik SR, et al. Interleukin-1 $\beta$ triggers the differentiation of macrophages with enhanced capacity to present mycobacterial antigen to T cells. Immunology 2014;141:174-80.

19 Seo S-U, Kwon H-J, Ko H-J, et al. Type I interferon signaling regulates $\mathrm{Ly} 6 \mathrm{C}(\mathrm{hi})$ monocytes and neutrophils during acute viral pneumonia in mice. PLoS Pathog 2011;7:e1001304.

20 Lamb DJ, Modjtahedi H, Plant NJ, et al. EGF mediates monocyte chemotaxis and macrophage proliferation and EGF receptor is expressed in atherosclerotic plaques. Atherosclerosis 2004;176:21-6.

21 Czepluch FS, Olieslagers S, van Hulten R, et al. VEGF-A-induced chemotaxis of CD16+ monocytes is decreased secondary to lower VEGFR-1 expression. Atherosclerosis 2011;215:331-8.

22 Lessard A-J, LeBel M, Egarnes B, et al. Triggering of NOD2 receptor converts inflammatory Ly $6 C^{\text {high }}$ into Ly $6 C^{\text {low }}$ monocytes with patrolling properties. Cell Rep 2017;20:1830-43.

23 Briseño CG, Haldar M, Kretzer NM, et al. Distinct transcriptional programs control Cross-Priming in classical and monocyte-derived dendritic cells. Cell Rep 2016;15:2462-74.

24 Auffray C, Fogg D, Garfa M, et al. Monitoring of blood vessels and tissues by a population of monocytes with patrolling behavior. Science 2007;317:666-70.

25 Koenis DS, Medzikovic L, van Loenen PB, et al. Nuclear receptor Nur77 limits the macrophage inflammatory response through transcriptional reprogramming of mitochondrial metabolism. Cell Rep 2018;24:2127-40.

26 Wu X, Chen Y, Sun R, et al. Impairment of hepatic NK cell development in IFN- $\gamma$ deficient mice. Cytokine 2012;60:616-25.

27 Shimozato O, Ortaldo JR, Komschlies KL, et al. Impaired NK cell development in an IFN- $\gamma$ transgenic mouse: aberrantly expressed IFN- $\gamma$ enhances hematopoietic stem cell apoptosis and affects NK cell differentiation. J Immunol 2002;168:1746-52. 
28 Choi BK, Kim YH, Kim CH, et al. Peripheral 4-1BB signaling negatively regulates $\mathrm{NK}$ cell development through IFN-gamma. J Immunol 2010;185:1404-11.

29 Lin Q, Rong L, Jia X, et al. IFN- $\gamma$-dependent NK cell activation is essential to metastasis suppression by engineered Salmonella. Nat Commun 2021;12:2537.

30 Wendel M, Galani IE, Suri-Payer E, et al. Natural killer cell accumulation in tumors is dependent on IFN-gamma and CXCR3 ligands. Cancer Res 2008;68:8437-45.

31 Chiossone L, Chaix J, Fuseri N, et al. Maturation of mouse NK cells is a 4-stage developmental program. Blood 2009;113:5488-96.

32 Robertson MJ. Role of chemokines in the biology of natural killer cells. J Leukoc Biol 2002;71:173-83.

33 Bernardini G, Gismondi A, Santoni A. Chemokines and NK cells: regulators of development, trafficking and functions. Immunol Lett 2012;145:39-46.

34 Huntington ND, Legrand N, Alves NL, et al. IL-15 trans-presentation promotes human NK cell development and differentiation in vivo. J Exp Med 2009;206:25-34.

35 Kumar P, Rajasekaran K, Nanbakhsh A, et al. IL-27 promotes NK cell effector functions via Maf-Nrf2 pathway during influenza infection. Sci Rep 2019;9:4984.

36 Green DS, Young HA, Valencia JC. Current prospects of type II interferon $\gamma$ signaling and autoimmunity. J Biol Chem 2017;292:13925-33.

37 Asada S, Daitoku H, Matsuzaki H, et al. Mitogen-activated protein kinases, ERK and p38, phosphorylate and regulate FoxO1. Cell Signal 2007;19:519-27.

38 Tzivion G, Dobson M, Ramakrishnan G. FoxO transcription factors; regulation by AKT and 14-3-3 proteins. Biochim Biophys Acta 1813;2011:1938-45.

39 Chen J, Feng X, Desierto MJ, et al. IFN- $\gamma$-mediated hematopoietic cell destruction in murine models of immune-mediated bone marrow failure. Blood 2015;126:2621-31.

40 Newton RH, Shrestha S, Sullivan JM, et al. Maintenance of CD4 T cell fitness through regulation of Foxo1. Nat Immunol 2018;19:838-48.
41 Ouyang W, Liao W, Luo CT, et al. Novel Foxo1-dependent transcriptional programs control T(reg) cell function. Nature 2012;491:554-9.

42 Sander S, Chu VT, Yasuda T, et al. PI3 kinase and FOXO1 transcription factor activity differentially control B cells in the germinal center light and dark zones. Immunity 2015;43:1075-86.

43 Tsuchiya K, Westerterp M, Murphy AJ, et al. Expanded granulocyte/ monocyte compartment in myeloid-specific triple FoxO knockout increases oxidative stress and accelerates atherosclerosis in mice. Circ Res 2013;112:992-1003.

44 Kitamura T. The role of FOXO1 in $\beta$-cell failure and type 2 diabetes mellitus. Nat Rev Endocrinol 2013;9:615-23.

45 Miao J, Ling AV, Manthena PV, et al. Flavin-containing monooxygenase 3 as a potential player in diabetes-associated atherosclerosis. Nat Commun 2015;6:6498.

46 Yoshida N, Yamamoto H, Shinke T, et al. Impact of CD14 ${ }^{++}$CD16 ${ }^{+}$ monocytes on plaque vulnerability in diabetic and non-diabetic patients with asymptomatic coronary artery disease: a crosssectional study. Cardiovasc Diabetol 2017;16:96.

47 Annett S, Moore G, Robson T. Obesity and cancer metastasis: molecular and translational perspectives. Cancers 2020;12 doi:10.3390/cancers12123798

48 Ren J, Wang Q, Morgan S, et al. Protein kinase C- $\delta$ (PKCdelta) regulates proinflammatory chemokine expression through cytosolic interaction with the NF- $\mathrm{KB}$ subunit p65 in vascular smooth muscle cells. J Biol Chem 2014;289:9013-26.

49 Briand O, Helleboid-Chapman A, Ploton M, et al. The nuclear orphan receptor Nur77 is a lipotoxicity sensor regulating glucoseinduced insulin secretion in pancreatic $\beta$-cells. Mol Endocrinol 2012;26:399-413.

50 Kubo H, Mensurado S, Gonçalves-Sousa N, et al. Primary tumors limit metastasis formation through induction of IL15-Mediated crosstalk between patrolling monocytes and NK cells. Cancer Immunol Res 2017;5:812-20. 